\title{
An Experimental investigation of the damaged B.F.I. Beam repaired by CFRP under the Static and fatigue loads
}

\author{
Dr. Hala M. R. Abusafa \\ Lecturer, Civil Department, Faculty of Engineering, Benha Univ., Egypt \\ Corresponding Author: Dr. Hala M. R. Abusafa
}

\begin{abstract}
The objective of this paper is to investigate the Structural behavior of the damaged steel B.F.I. Beam (No. 10) under fatigue load (repeated load by $40 \%$ the value that produces a static failure) and make a comparison with the static loads for the same specimen. Which repaired and reinforced by Carbon fiber polymers strips (CFRP) $(3 * 10 \mathrm{~cm} * 100 \mathrm{~cm})$, fixed at the center of the tension flange and 8 strips $(8 * 8 \mathrm{~mm} * 10 \mathrm{~mm})$ were distributed and fixed to the two faces of the web. The damage is created by notching $(4 \mathrm{~mm})$ in the center of the tension flange for the six beams and two beams were damaged by the failure test of the two control beams. We have ten B.F.I. Beams, five beams were tested under static load and the other five beams under fatigue load with different ways of reinforcing by the layers of CFRP. We make an experimental comparison between the behavior for the ten beams under static and fatigue loads. We noticed that CFRP patching resulted in improvement in fatigue life of the damaged beams of up to 6.4 times over that of unrepaired beams, and to $1.8 \%$ for static load cases, CFRP strips moderate fatigue crack propagation. The reinforcing to the web work as a stiffeners improve the shear failure and the deflection.
\end{abstract}

Keywords: Steel B.F.I beams. Fatigue load; Static load; Experiment; CFRP

\section{INTRODUCTION}

The issue of infra structure management and rehabilitation is one of the primary interests in civil engineering community. Constructed bridge members deteriorate because of aging, corrosion, increased service loads and traffic volume, use of deicing salts, and collision of heavy trucks [1-4].The fatigue failure of metals is the well-known type of failure that occurs after the repetition of several cycles, from a few to millions, of stresses applied to the specimen by repeated load without breakages during the fatigue life. The designer can obtain a good design, without excessive over sizing or risk of breakage. It is well known that the maximum value of the repeated load that produces a fatigue failure is roughly $50 \%$ the value that produces a static failure [5]. CFRP patching resulted in improvement in fatigue life of damaged beams of up to 3.4 times over that of unrepaired beams. Nozaka et al. [6] considered the performance of combinations of two CFRP materials and five adhesive systems to enhance the fatigue behavior of steel sections. They reported the greatest increase in fatigue strength resulting from the system combining the CFRP and adhesive having the lowest module of elasticity of those considered. O'Neill et al. [7]. The use of externally bonded fiber-reinforced polymer (FRP)composite patches has been shown to be an effective method to extend the fatigue life of cracked or fatigue sensitive metallic elements[8,9,10]. The bonded patches have bridging effects on fatigue cracks which complicates the fatigue crack growth (FCG) analysis of FRP patched metallic elements. Numerical models have been proposed to predict the fatigue life and perform the FCG analysis. The models fall into two major methodologies: i) damage accumulation rules based on the material stress range vs. number of fatigue cycles to failure (S-N) [8].CFRP strips moderate fatigue crack propagation in three different ways: (a) by reducing the stress range around the crack tip; (b) by reducing the crack opening displacement and (c) by promoting crack closure. The interaction between CFRP strips and damage (crack) propagation at the mid-span of steel beams under fatigue loading was recently analyzed [11, 12].Fatigue loading in stress concentration zones can lead to crack nucleation and growth and finally to the complete failure of the structural element. Concerning the fatigue failure of steel beams, several repair techniques may be considered to extend the fatigue finite life of the structural element (fatigue life time)[13]. 


\subsection{Test program}

\section{EXPERIMENTAL PROGRAM}

The details of the experimental program and the test machine in the lab were provided in Table.1. and fig .1. (a, b, c). We tested ten B.F.I. beams with dimensions $10 \times 10 \times 1500 \mathrm{~cm}$. They tested under two points in the center of the beam and far from together by $300 \mathrm{~mm}$ as shown in fig.1. We tested five beams under static load and the other five beams were tested under fatigue load (repeated load). There are two control beams the first was tested under static load and the other beam under fatigue load, also two beams were notched $4 \mathrm{~mm}$ in the tension flange and tested under static and fatigue loads (case one). There are two beams had been notched in the tension flange $4 \mathrm{~mm}$ and rehabilitation by three layers of CFRP strips 10x100 cm fixed in the center of the bottom flange ( tension flange) and tested under the static and fatigue loads ( case two ), the other two beams were tested under the same loads but we put extra eight strips of CFRP fixed and distributed to the length of the web ( the strips distributed in the two faces) ( case three), the two control beams which damaged after the testes and were reinforced by three layers in the tension flange $(10 * 100 \mathrm{~cm})$ and four strips fixed to the every face of the web $(10 \times 8 \mathrm{~cm})$ ( case four).The CFRP strips $(10 \times 100 \mathrm{~cm})$ (sika Wrap-230C) Table.2. and Fig.2.showing the CFRP ( in the vertical sec $(a, b)$ and 3D sec) which fixed in a three layers in six beams at the center of the tension flange, and for the two sides of the web (4strips 10x10) for four damaged steel beams . The three rehabilitations reinforced specimens were subjected to static loads and the other three beams under fatigue loads at the laboratory.

\subsection{Specimen details and preparation}

The details of the experimental program and the results were written in the Table.1. Which explained the load type for all the beams, the initial notching $(4 \mathrm{~mm})$, the NO.? of reinforcing layers of CFRP, the failure loads for static cases and the final NO. of the cycles in fatigue loads, the max. deflections and explained the final cracks (the tall crack in the web and the wide in the flange) for all the ten beams.

Table1. The experimental program and the results.

\begin{tabular}{|c|c|c|c|c|c|c|c|c|c|c|}
\hline \multirow{2}{*}{\multicolumn{2}{|c|}{ Specimen No. }} & \multirow{3}{*}{$\begin{array}{l}\text { Load } \\
\text { type }\end{array}$} & \multirow{3}{*}{$\begin{array}{c}\begin{array}{c}\text { First crack } \\
\text { notched } \\
\text { nmm }\end{array} \\
\end{array}$} & \multicolumn{2}{|c|}{$\begin{array}{l}\text { No, of CFRP } \\
\text { reinforcing } \\
\text { layers }\end{array}$} & \multirow{2}{*}{$\begin{array}{l}\text { Load } \\
\text { rang } \\
\text { applied } \\
\mathrm{kn}\end{array}$} & \multirow{3}{*}{$\begin{array}{c}\text { No. of } \\
\text { cycles }\end{array}$} & \multirow{3}{*}{$\begin{array}{c}\text { The max } \\
\text { deflection } \\
\text { mm }\end{array}$} & \multicolumn{2}{|c|}{$\begin{array}{c}\text { Final crack } \\
\text { mm }\end{array}$} \\
\hline & & & & Tengisen & & & & & \multirow{2}{*}{$\begin{array}{c}\text { Tall } \\
\text { in } \\
\text { web } \\
+\end{array}$} & \multirow{2}{*}{$\begin{array}{c}\text { Wide } \\
\text { in } \\
\text { flange } \\
\text { mm } \\
\end{array}$} \\
\hline Control & $\mathrm{CI}$ & & & - & - & 166.13 & & & & \\
\hline Control & $\mathrm{CIR}$ & fatigue & - & - & - & - & 65 & $\$ 6.2$ & - & - \\
\hline \multirow{2}{*}{ Case 1} & $\mathrm{CII}$ & static & $4 \mathrm{~mm}$ & - & - & 65.3 & - & 9 & 10 & 13 \\
\hline & CIRI & fatigue & $4 \mathrm{~mm}$ & - & - & - & 41 & 23.5 & 12 & 15 \\
\hline \multirow{2}{*}{ Case 2} & $\mathrm{Cl}_{2}$ & static & $4 \mathrm{~mm}$ & 3 & $\cdot$ & 80 & 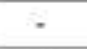 & 34 & 17 & 10 \\
\hline & CIR2 & fatigue & $4 \mathrm{~mm}$ & 3 & $\cdot$ & - & 420 & 58 & 20 & 10 \\
\hline \multirow{2}{*}{ Case 3} & $\mathrm{Cl} 3$ & static & $4 \mathrm{~mm}$ & 3 & $4 \times 2$ & 118.3 & - & 38.6 & 35 & 12 \\
\hline & $\mathrm{CIR} 3$ & fatigue & $4 \mathrm{~mm}$ & 3 & $4 \times 2$ & - & 480 & 40 & 50 & 13 \\
\hline \multirow{2}{*}{ Case 4} & $\begin{array}{l}\mathrm{CI} \\
\text { repair }\end{array}$ & static & damaged & 3 & $4 \times 2$ & 200 & - & 12 & - & - \\
\hline & $\begin{array}{l}\text { CIR } \\
\text { repair }\end{array}$ & fatigue & damaged & 3 & $4 \times 2$ & - & 500 & 16 & - & - \\
\hline
\end{tabular}

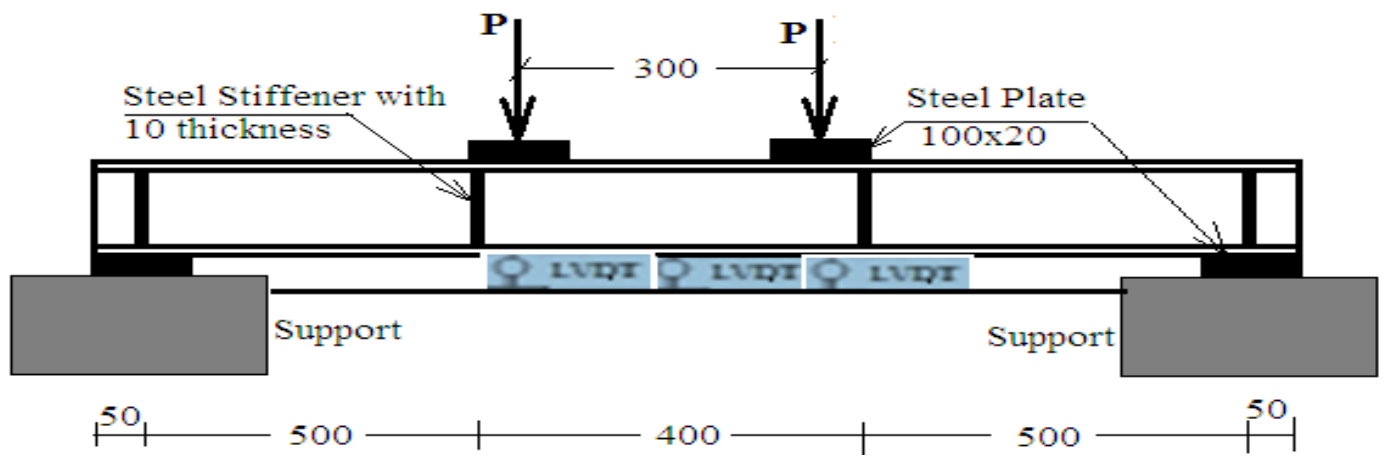

a) Details of The intact beam 


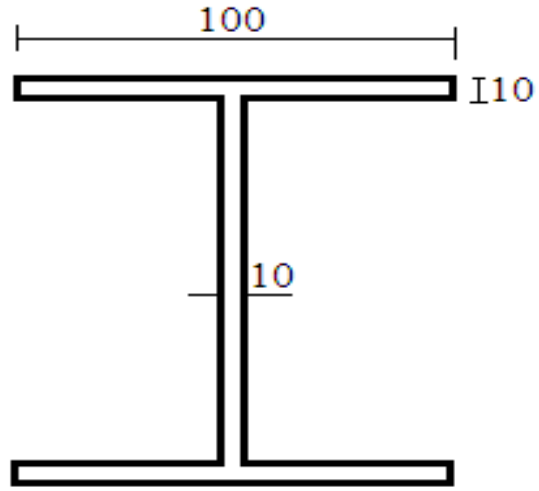

b) Cross section of the intact beam

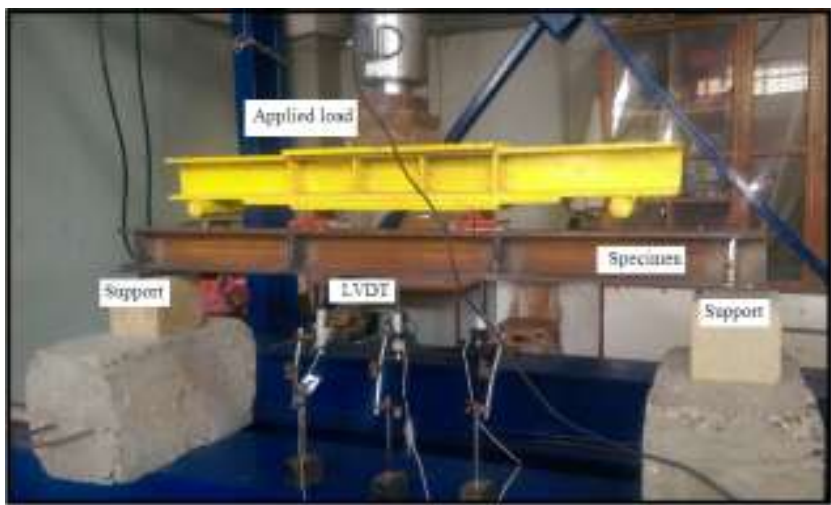

c) The experimental test system in the lab. Fig. 1: The details of specimen in the lab.

Table2. Mechanical properties of CFRP

\begin{tabular}{|c|c|}
\hline Property & Value \\
\hline Wrap length/roll & $\geq 50 \mathrm{~m}$ \\
\hline Wrap width & $300 / 600 \mathrm{~mm}$ \\
\hline Wrap thickness & $0.13 \mathrm{~mm}$ \\
\hline Areal weight & $0.230 \mathrm{~kg} / \mathrm{m} 2$ \\
\hline Fibre Density & $1.80 \mathrm{~g} / \mathrm{cm} 3$ \\
\hline Tensile strength of the fibers & $3500 \mathrm{MPa}$ \\
\hline Modulus of elasticity of fibers & $230 \mathrm{GPa}$ \\
\hline Fiber strain when failure & $1.6 \%$ \\
\hline
\end{tabular}

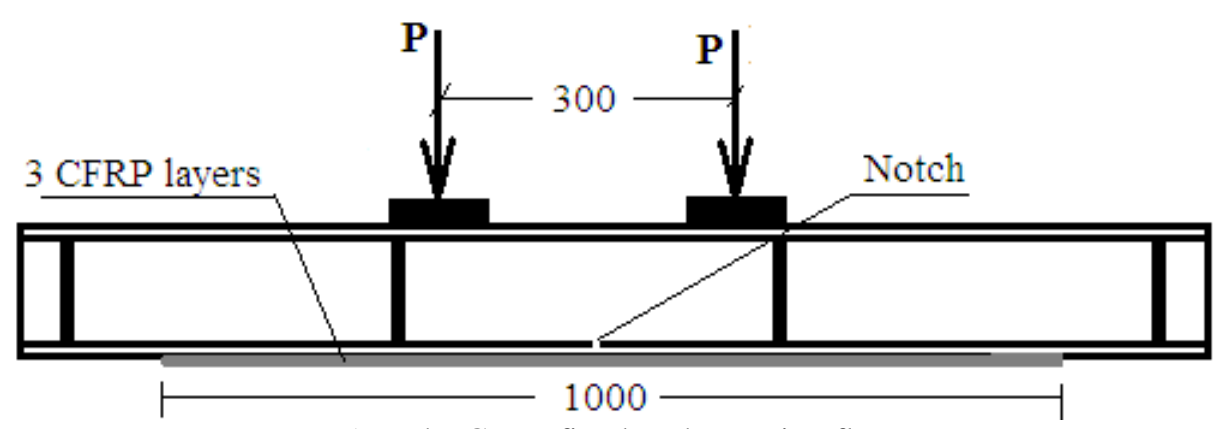

a) The CFRP fixed to the tension flange.

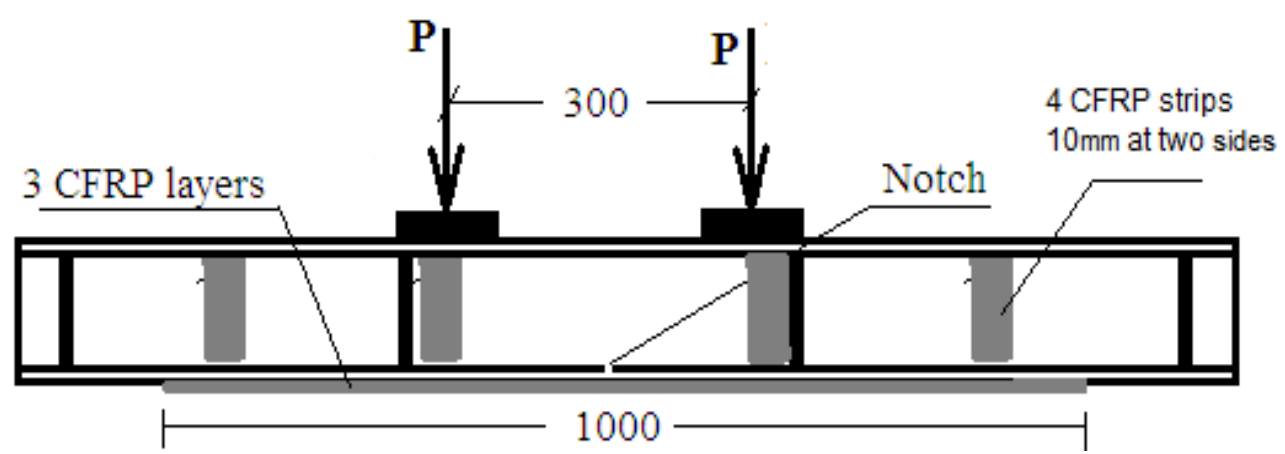

b) The CFRP strips fixed to the flange and the two sides of the web. 


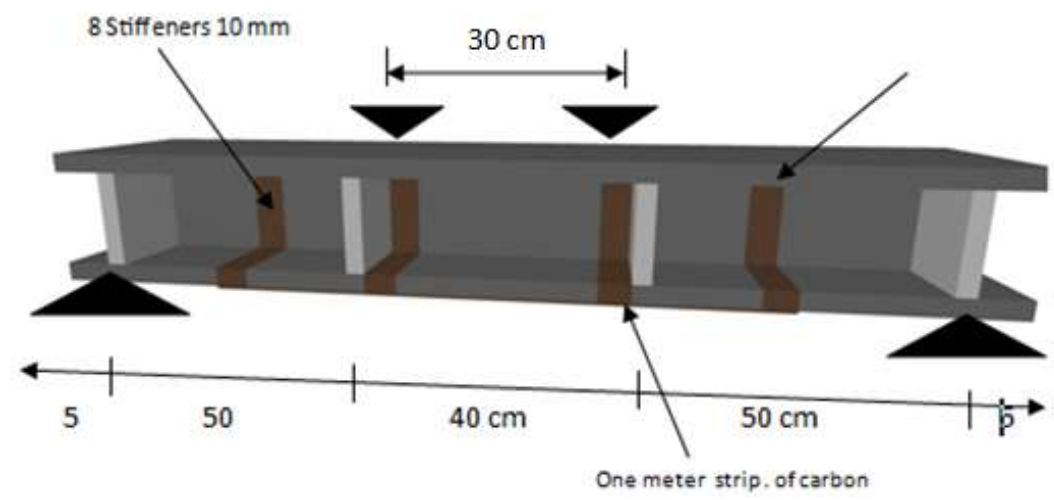

c) The repairing CFRP strips fixed at the flange and the web (3D).

Fig. 2: $(a, b, c)$ Showing the repaired method

\subsection{The applied loads}

\section{EXPERIMENTAL RESULTS}

The experimental results are detailed in Table 1, including: the ultimate load in the static case (200 kn) and the max number of cycles (500) to achieve a final crack length of about $50 \mathrm{~mm}$ and the normalized specimen stiffness at the initial and final crack size (from $4 \mathrm{~mm}$ to $13 \mathrm{~mm}$ ). In the static cases we noticed that the ultimate load in control beam( CI) was $166.13 \mathrm{kn}$, in the notched beam ( CI1) was $65.3 \mathrm{kn}$., but in the beam ( CI2) increased to $80 \mathrm{kn}$ which notched and strengthened by three layers of CFRP fixed at the bottom center of the flange, also the failure load was increased to $118.3 \mathrm{kn}$ in the beam (CI3) which notched and repaired by three layers of CFRP fixed to the tension flange and extra 8 vertical strips fixed and distributed to the two faces of the web and finally we repaired the damaged control beam after the test by the last system of repairing which failed under $200 \mathrm{kn}$. The case of fatigue load we used repeated load about the half of the static load in the same case of the beam. The number of the cycles was 65 in the control beam ( CIR),in the ( CIR1) was 41 cycle, but increases to 420 cycles ( by $6.5 \%$ ) in the strengthened flange beam ( CIR2) also, increased to 480 cycle ( $7.3 \%$ ) in the repaired beam( CIR3) in flange and web by CFRP and the No. of cycles increased to 500 by ( $7.7 \%)$ in ( CIR repairing)

\subsection{The deflection}

In the table1. and Fig.3. (the experimental test in the lab) we noticed that the deflection was $30.3 \mathrm{~mm}$ in (CI) and $34 \mathrm{~mm}$ in (CI2), 38.6mm in (CIR2), 40mm in ( CI3) which indicated to the good ductility with increasing the strengthening by CFRP in the static cases, also helping the beams to be stable under repeated loads and increase the cycles in the fatigue load. The CFRP reinforcements do not significantly improve the elastic structural response from the global point of view. The composite materials improve the local structural response through a significant increment of the local stiffness and strength .also the deflection decrease in the CI repairing to $12 \mathrm{~mm}$ and to $16 \mathrm{~mm}$ in CIR repairing which indicated to the steel stiffeners and CFRP strips on the web.

\subsection{The effect of CFRP of failure.}

Fig.4. Showing that the failure shape of the carbon. It must be taken into account that the CFRP reinforcement is usually bonded to the steel substrate by epoxy adhesive. Due to the high strength of the reinforcement and the steel substrate the adhesive layer is usually the weakest point of the system. Failure modes are associated to cohesive failure in the adhesive joint (generally at the steel-adhesive interface) and CFRP de bonding. Galvanic corrosion is also a potential problem since, when the carbon fibers are in contact with the steel surface, they produce a galvanic cell. On the other hand, FRP reinforcement cannot be efficiently applied to a non-smooth surface, as in the case of riveted girders due to the high rivets density. Finally, a critical point for heritage structures is due to the fact that reversibility of the strengthening system is highly recommended. The crack repair of fatigue damaged steel beams by using CFRP materials can be achieved in three different ways, the high reinforcement stiffness results in the reduction of the stress range around the crack tip. Besides, the use of CFRP strips bonded to the crack has an effect in bridging the crack lips, reducing the crack opening displacement and thus promoting crack closure. 


\subsection{The behavior of the beams under static and fatigue loads}

The curves in the shapes $1,2,3,4,5,6,7,8$, explained the behavior of the beams with its four cases under static and fatigue loads, making a good comparison between them in the static and fatigue cases. Shap1. Time load curves in the static loads. The load in CI1 less than the control beam by $0.39 \%$, but CI 2 increased by $1.23 \%$ than $\mathrm{CI} 1$, and $\mathrm{CI} 3, \mathrm{CI}$ repairing increased by $1.8 \%$ and $3.1 \%$ respectively than $\mathrm{CI} 1$ for the affecting of the CFRP. Shape2. Time -load curves in the fatigue loads which explained the number of the cycles to the time, which decreased in CIR1 by $63 \%$ than CIR, but increased in CIR2, , CIR3, CIR repairing by 6.5\%, 7.4\%, 7.7\% ( respectively) than CIR. Shape.3,4 are the time- deflection curves for the beams under static and fatigue load. In the static case the rate of the deflection increased by $1.1,1.3 \%$ in CI2, CI3 than CI, but decreased by $40 \%$ in

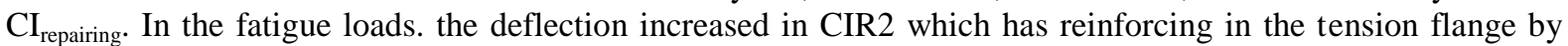
$1.03 \%$ but it decreased by $1.41 \%, 3.5 \%$ in CIR3, CIR repairing which had extra reinforcing in the web. Shapes.5,6. are the load- defl. curves in the static and fatigue loads. Shapes.7,8. Explained the comparison of the timestresses curves in the two cases of loads.

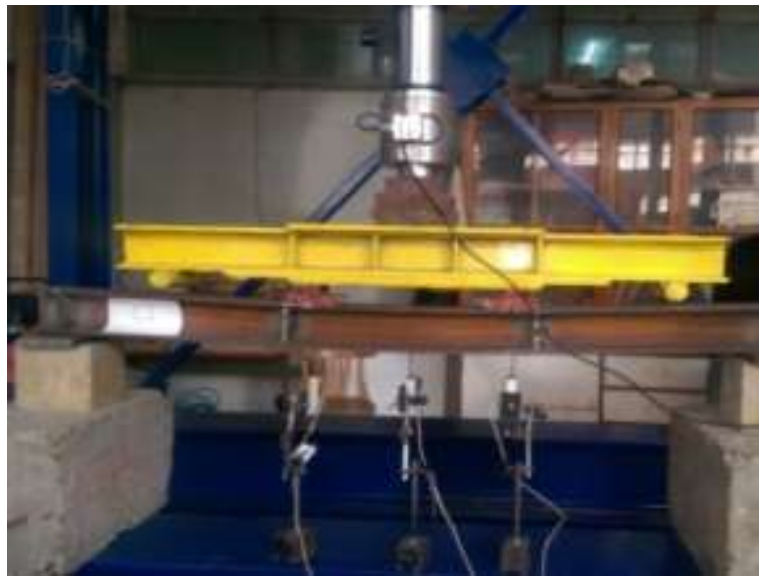

CI

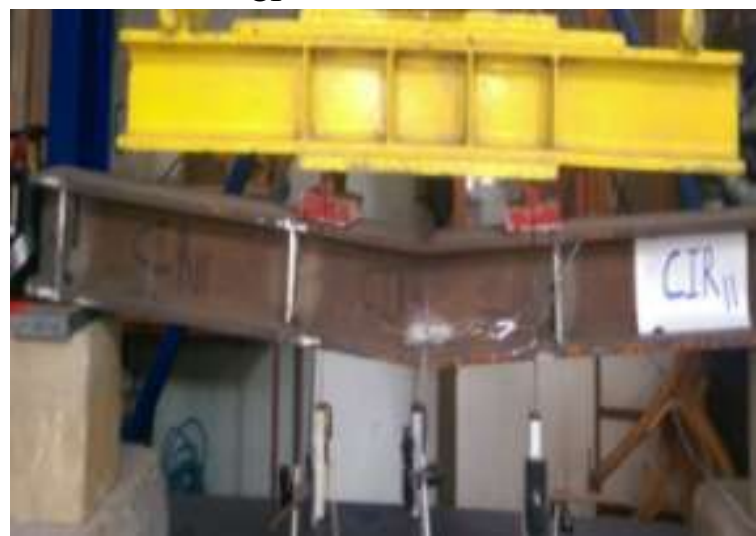

CI

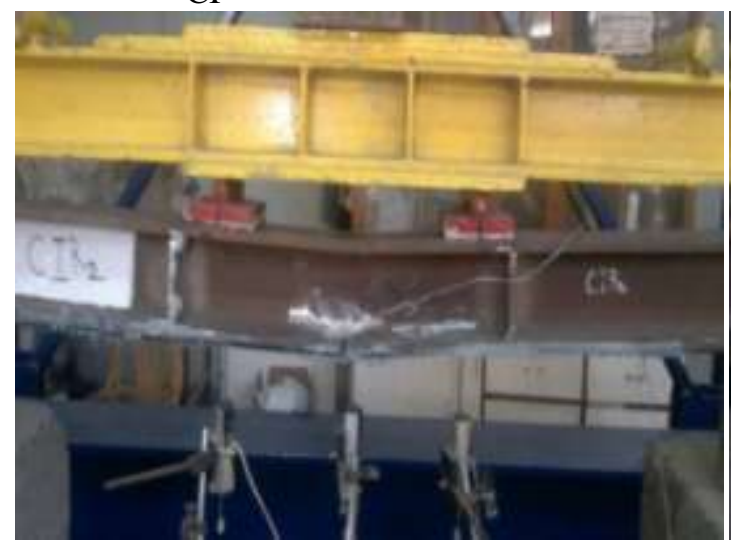

CI2

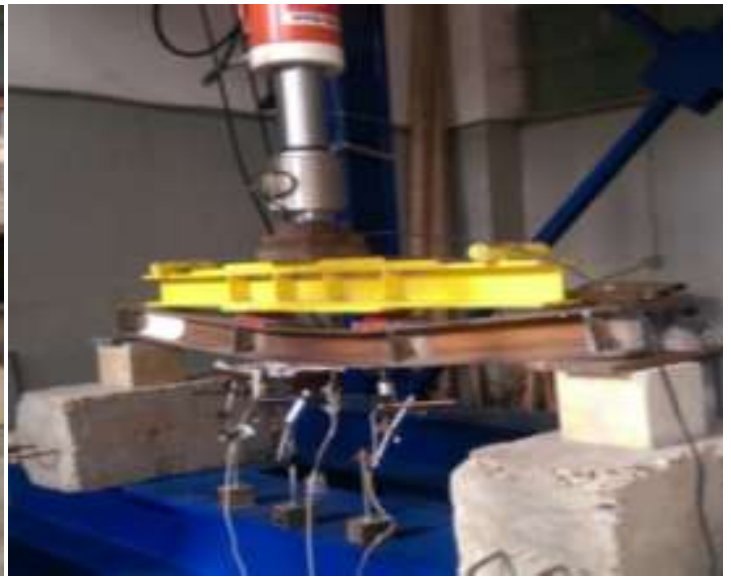

CIR

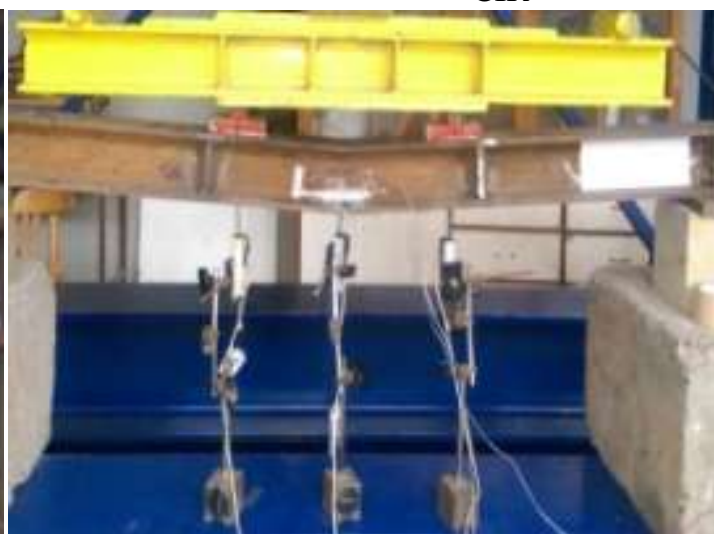

CIR 1

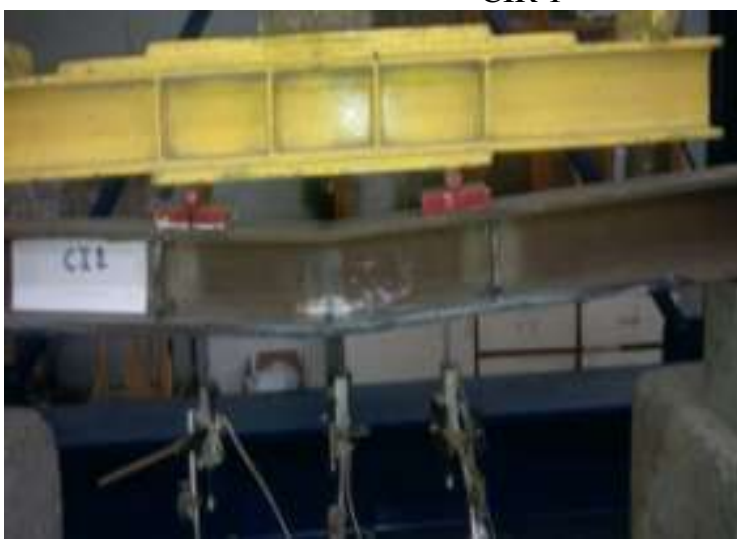

CIR2 


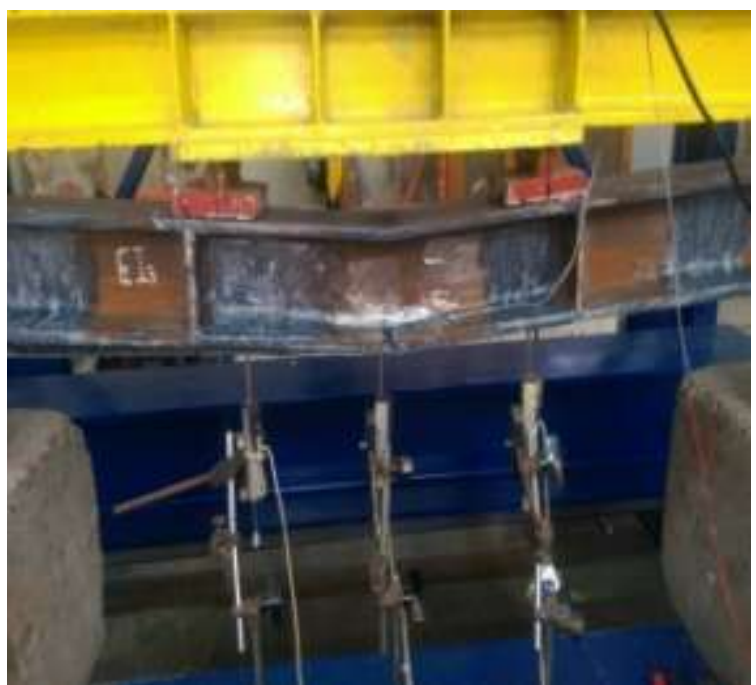

CI3

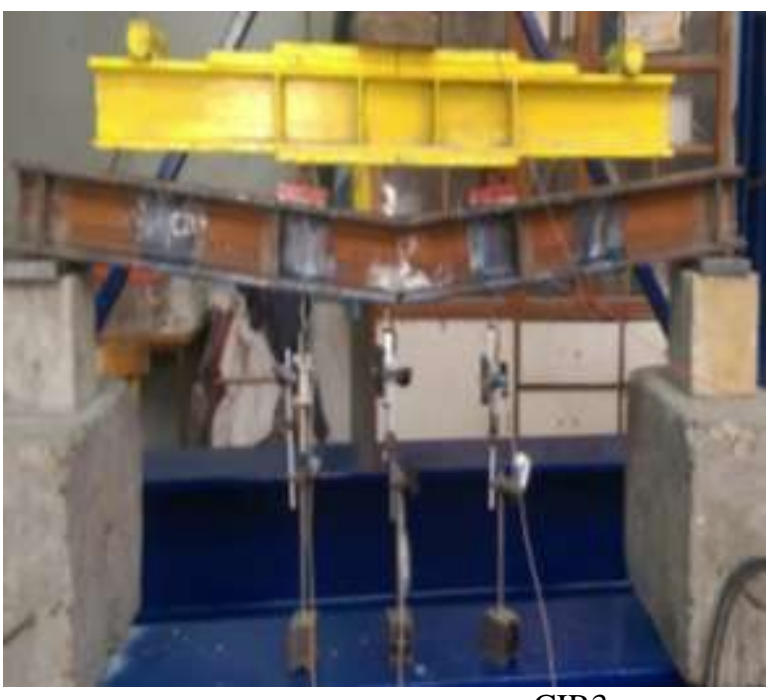

CIR3

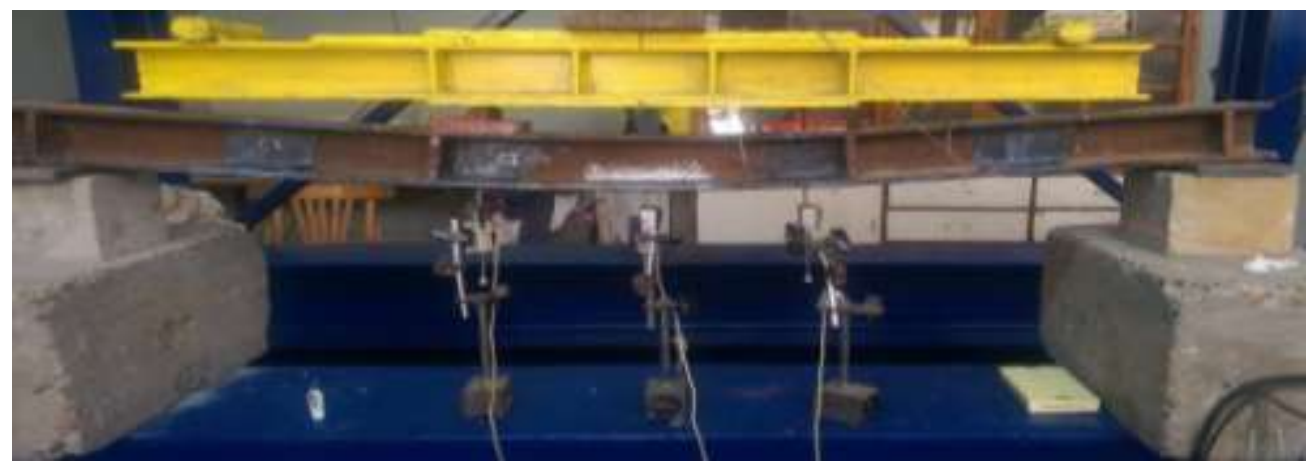

CI repairing

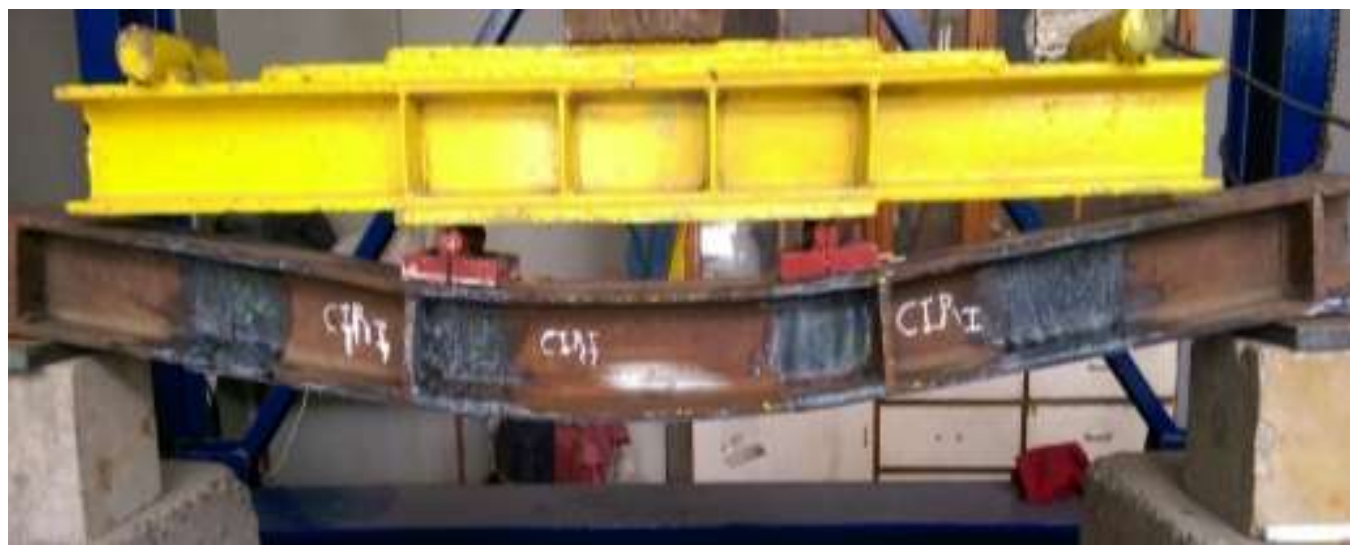

CIR repairing

Fig.3. the experimental programs for the all beams under the static and fatigue loads. 

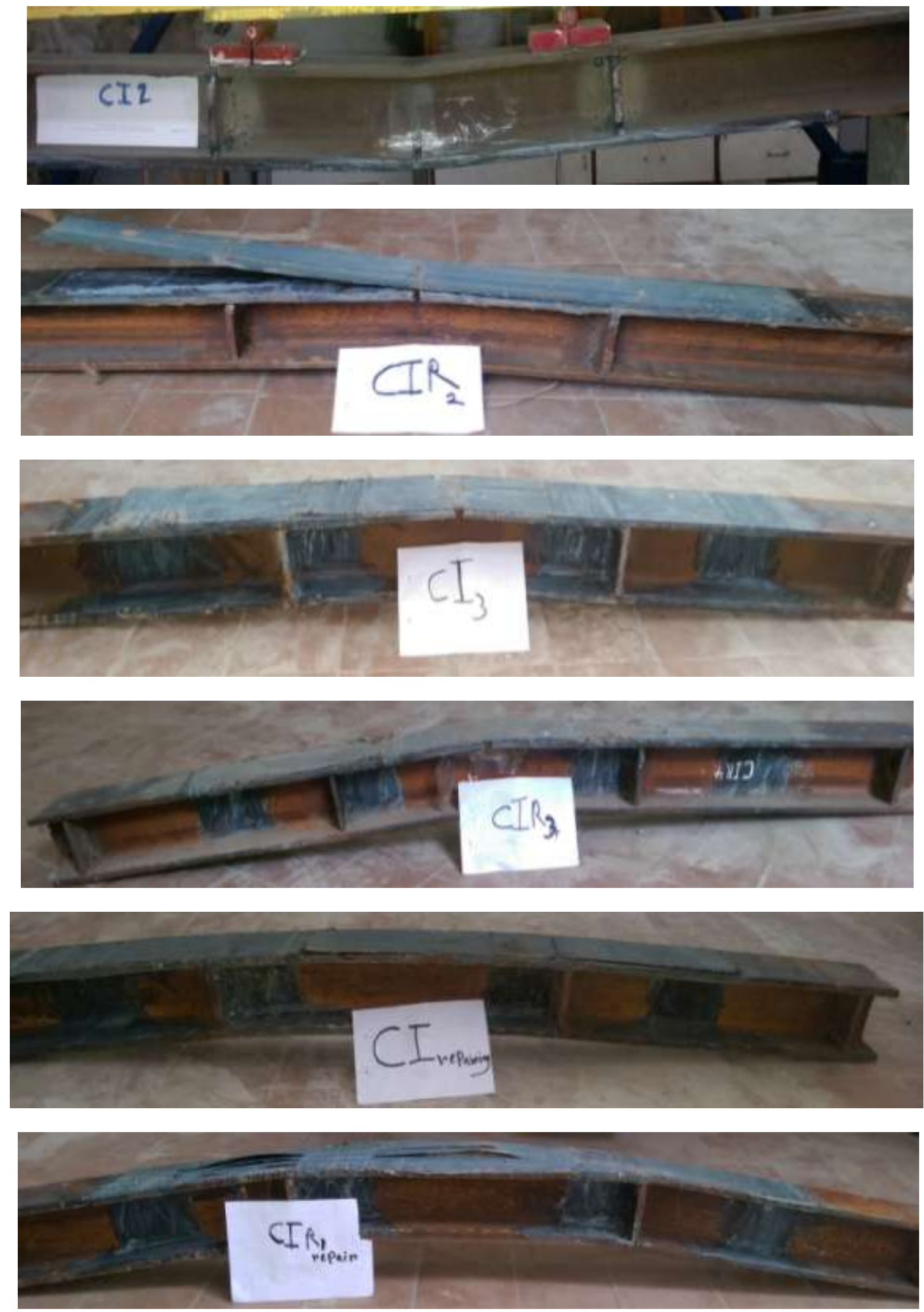

Fig.4. the shape of failure for the carbon under static and fatigue loads in the repairing cases. 

ISSN : 2248-9622, Vol. 7, Issue 7, ( Part -8) July 2017, pp.30-43
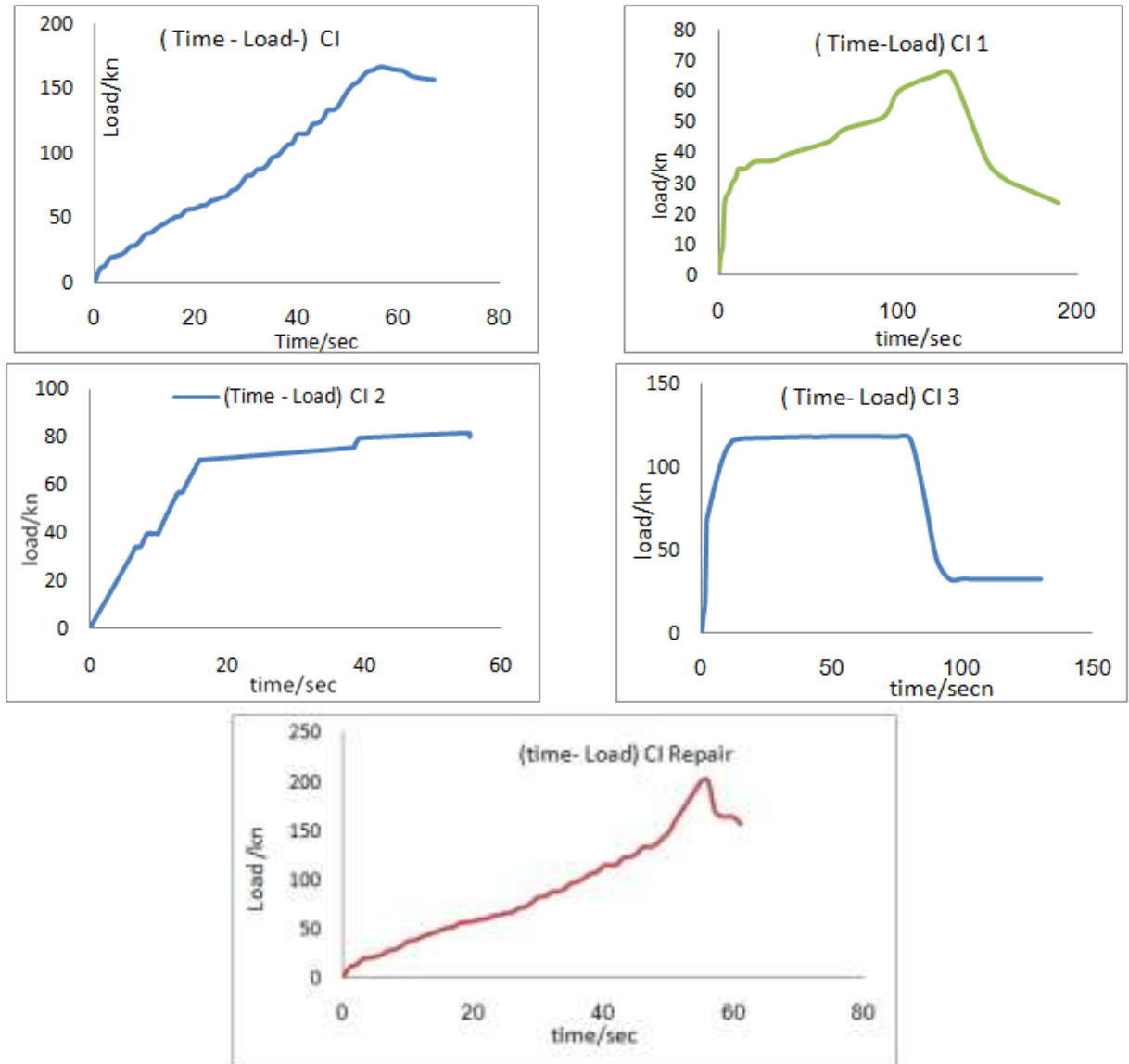

Shape1. The time - Load comparison of the behavior for the beams in the static case.
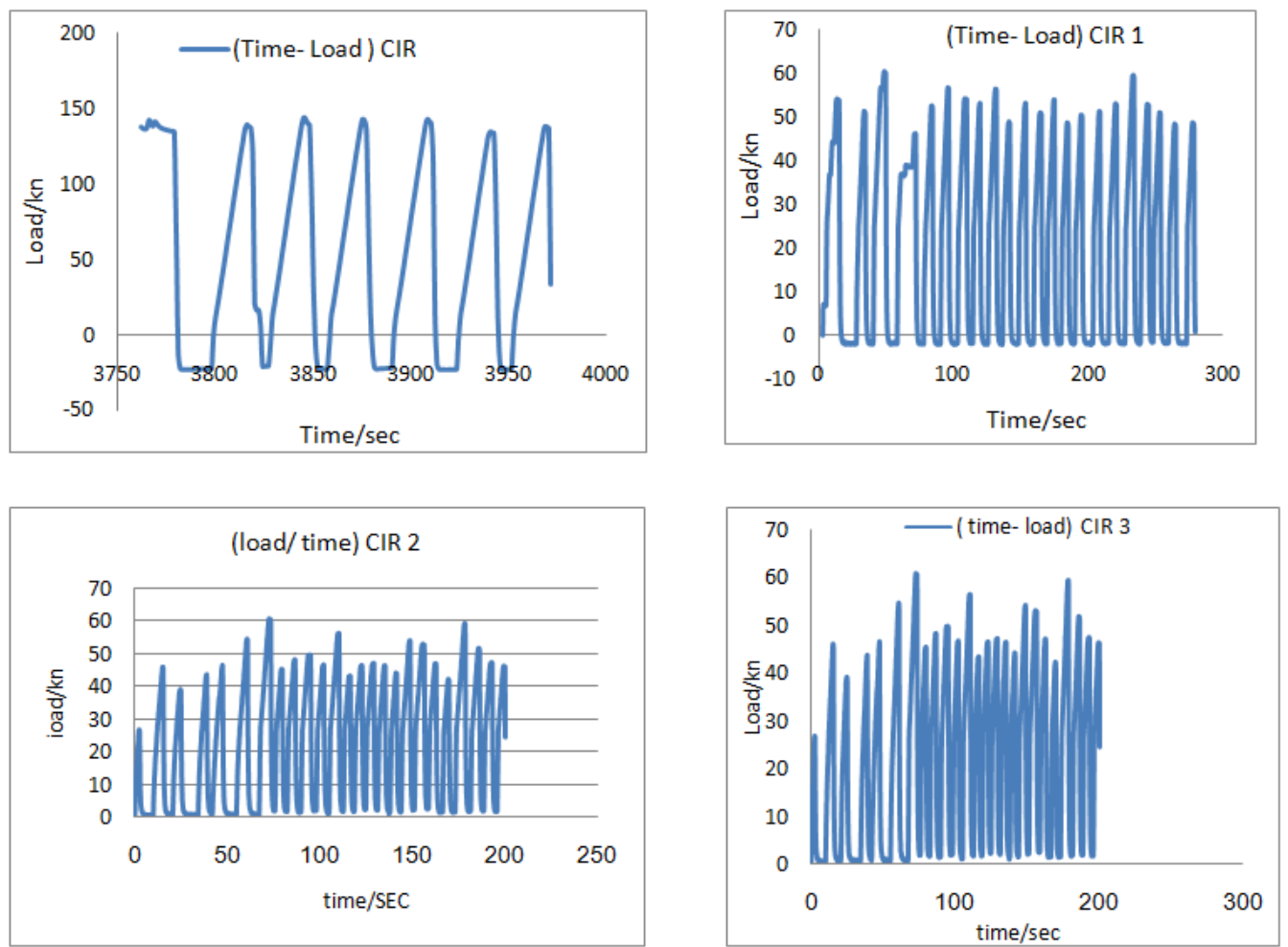


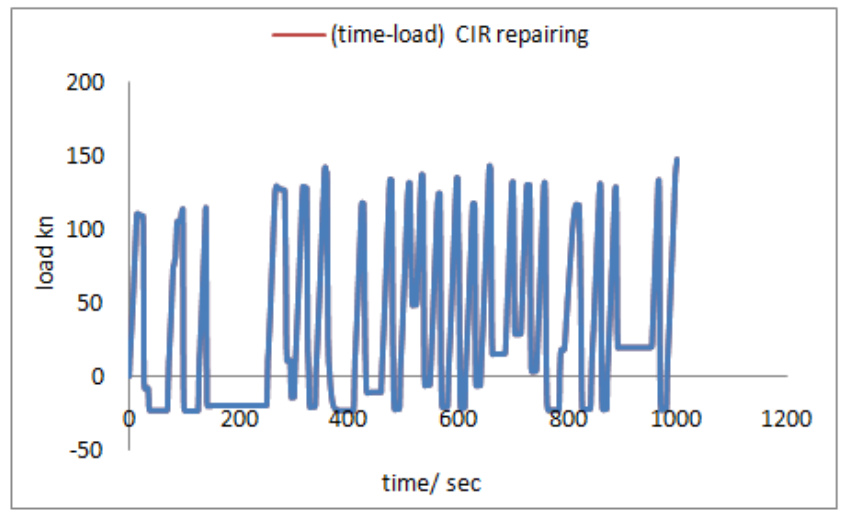

Shape2. The time - Load comparison of the behavior for the beams in the fatigue case
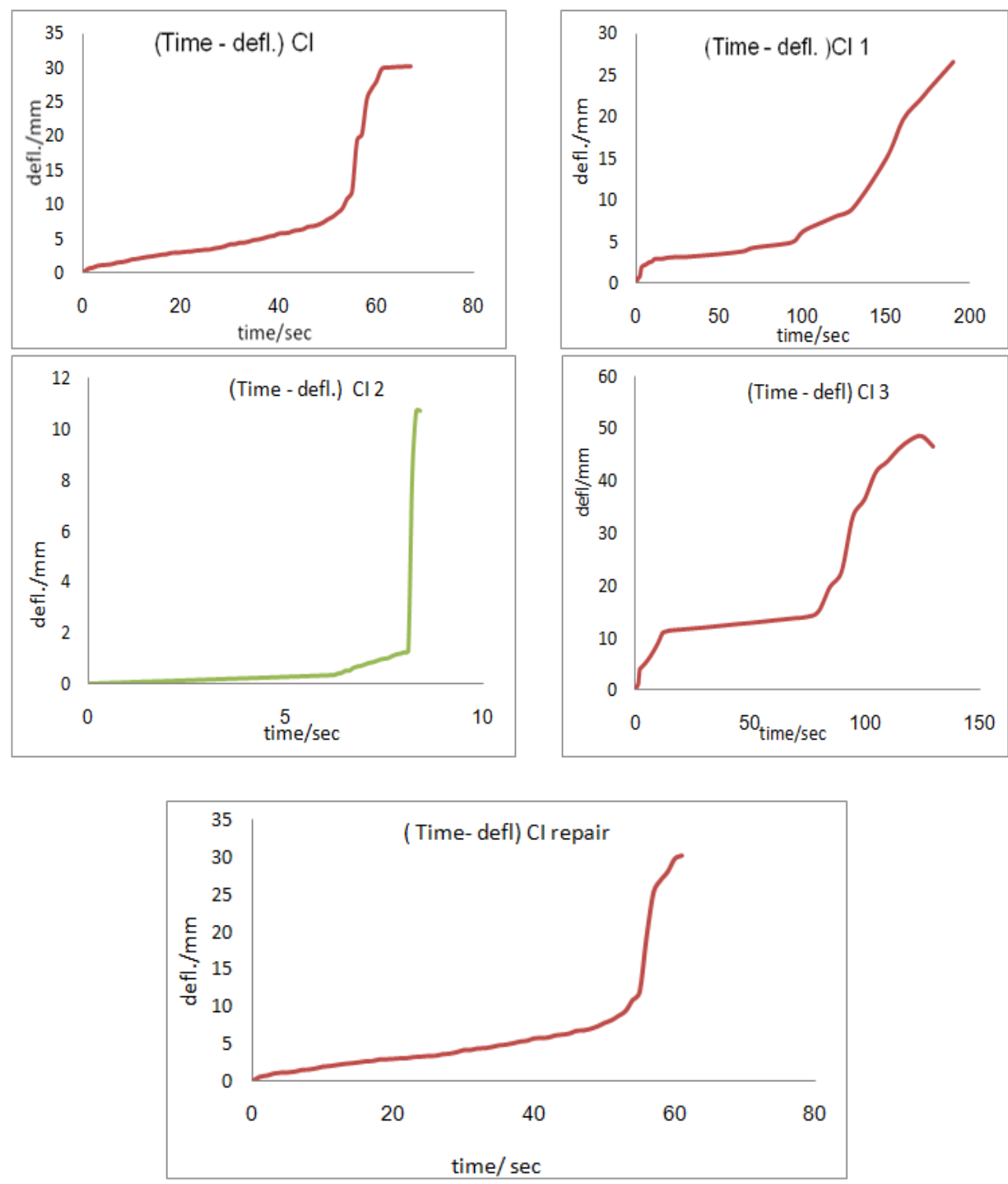

Shape3. The time - defl. Comparison of the behavior for the beams in the static case 

ISSN : 2248-9622, Vol. 7, Issue 7, ( Part -8) July 2017, pp.30-43
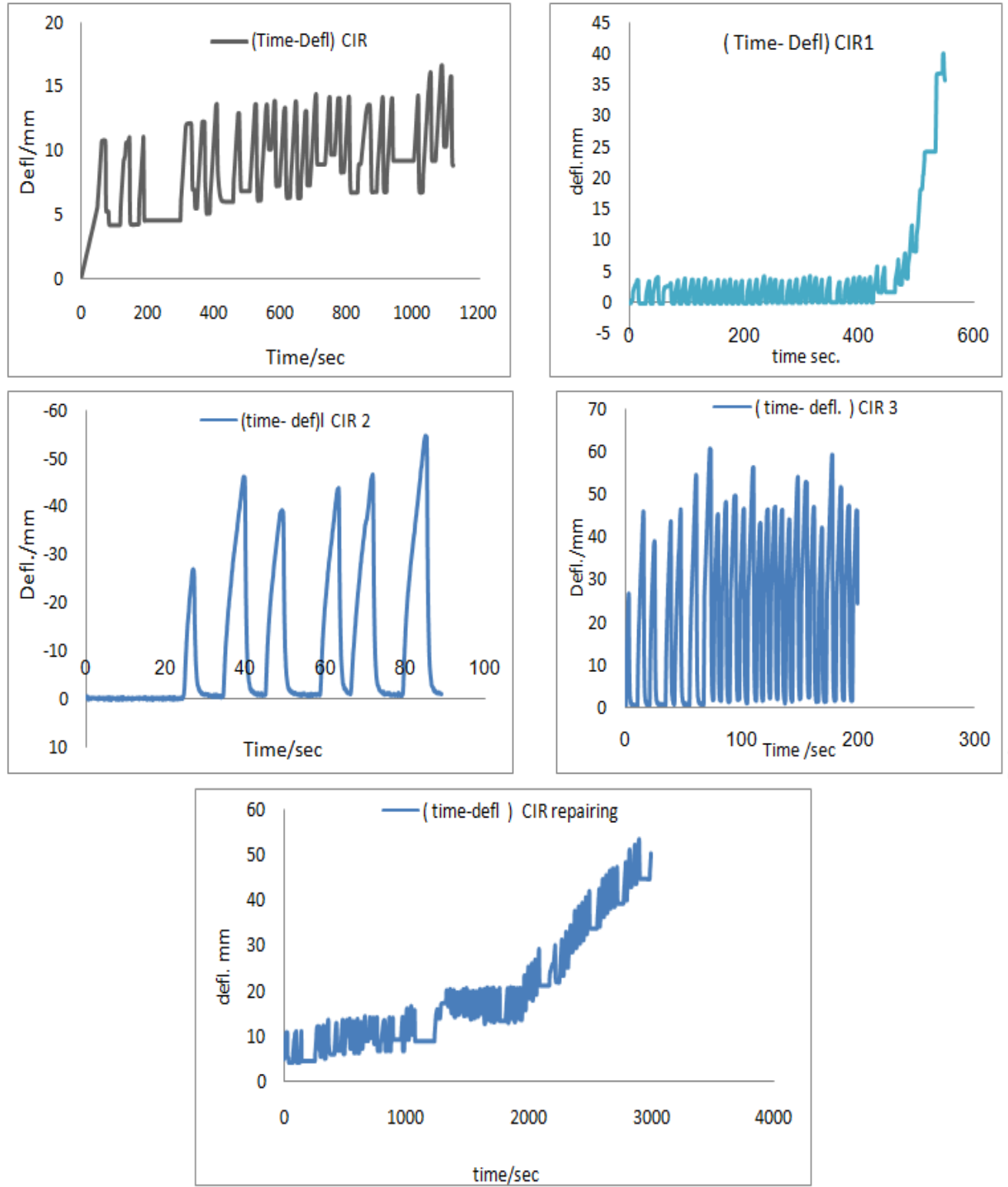

Shape4. The time - defl. Comparison of the behavior for the beams in the fatigue case.

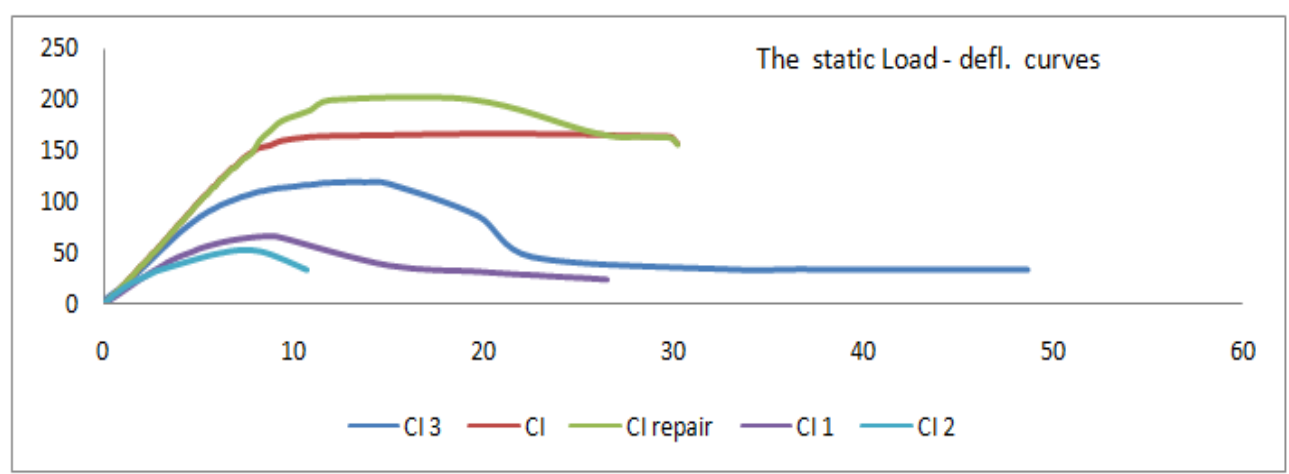



ISSN : 2248-9622, Vol. 7, Issue 7, ( Part -8) July 2017, pp.30-43
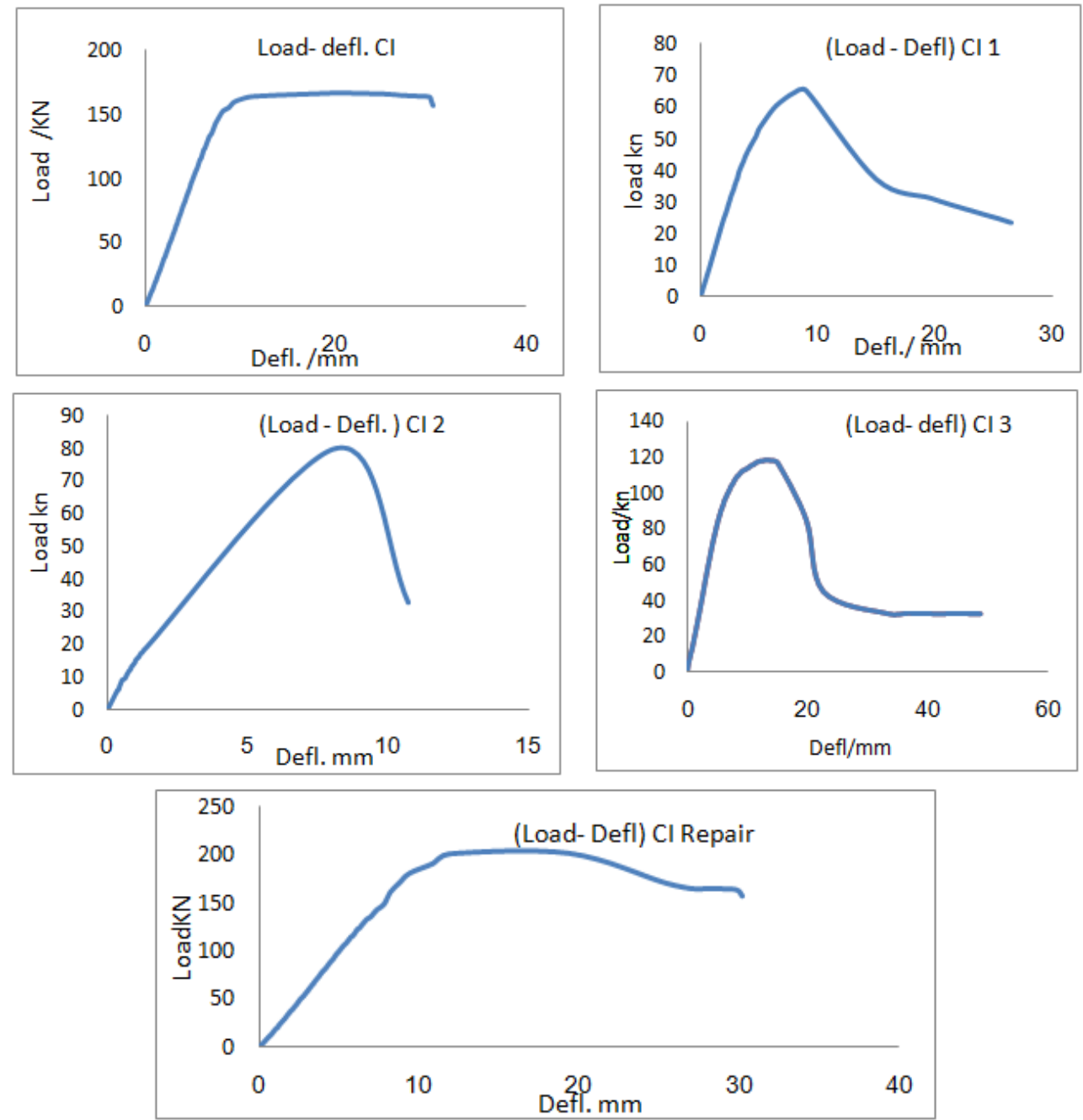

Shape5. The Load - Defl. Comparison of the behavior for the beams in the static cases.
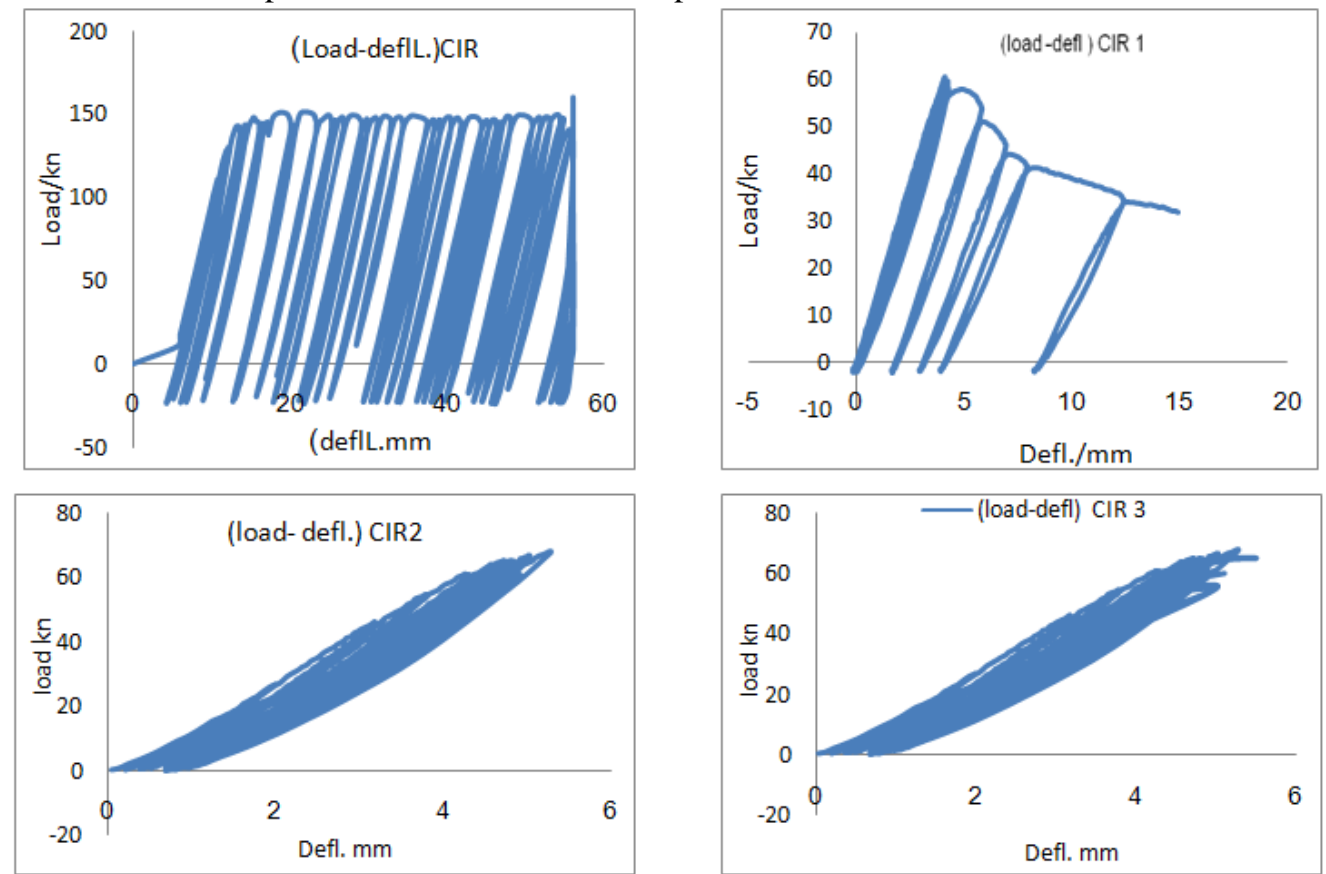


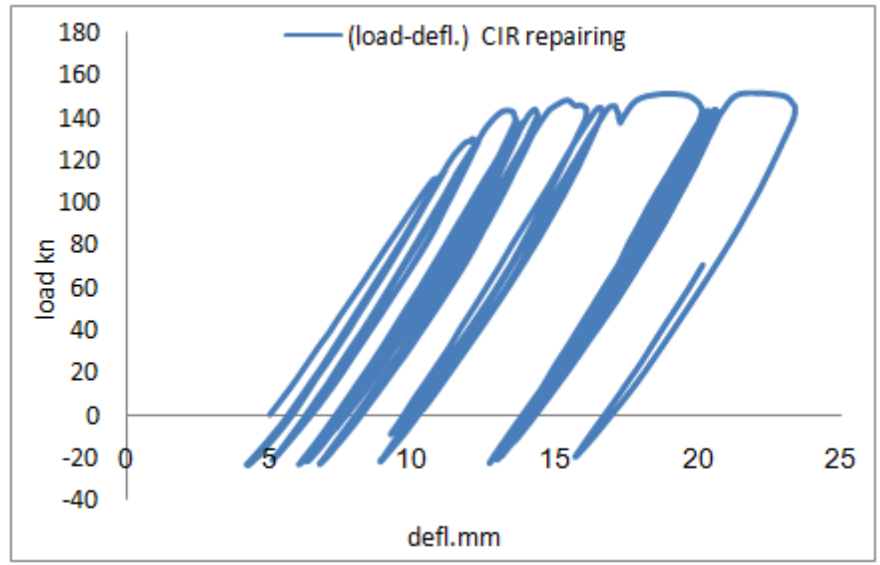

Shape6. The Load - Defl. Comparison of the behavior for the beams in the fatigue case
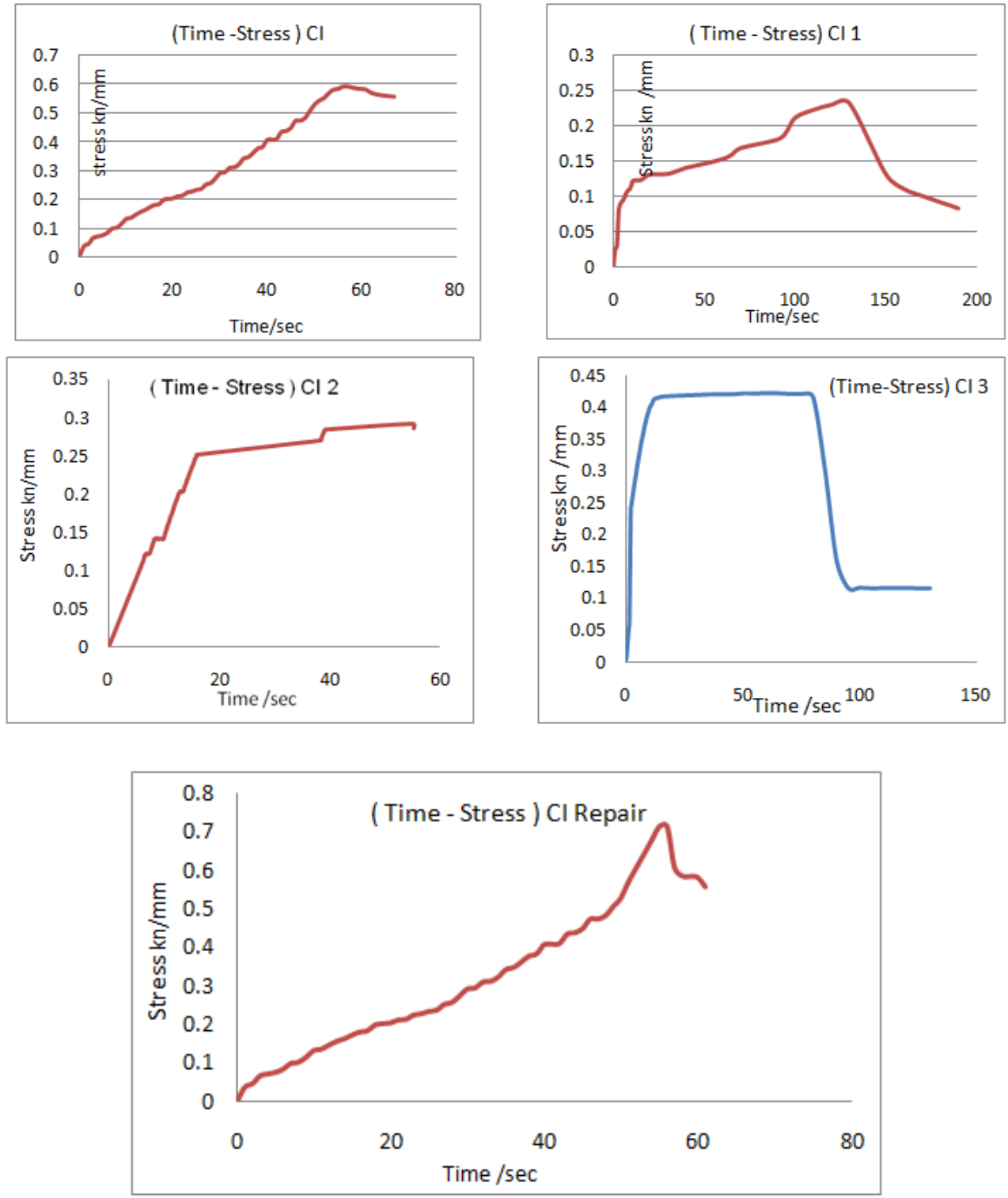

Shape7. The time- stresses Comparison of the behavior for the beams in the static case. 

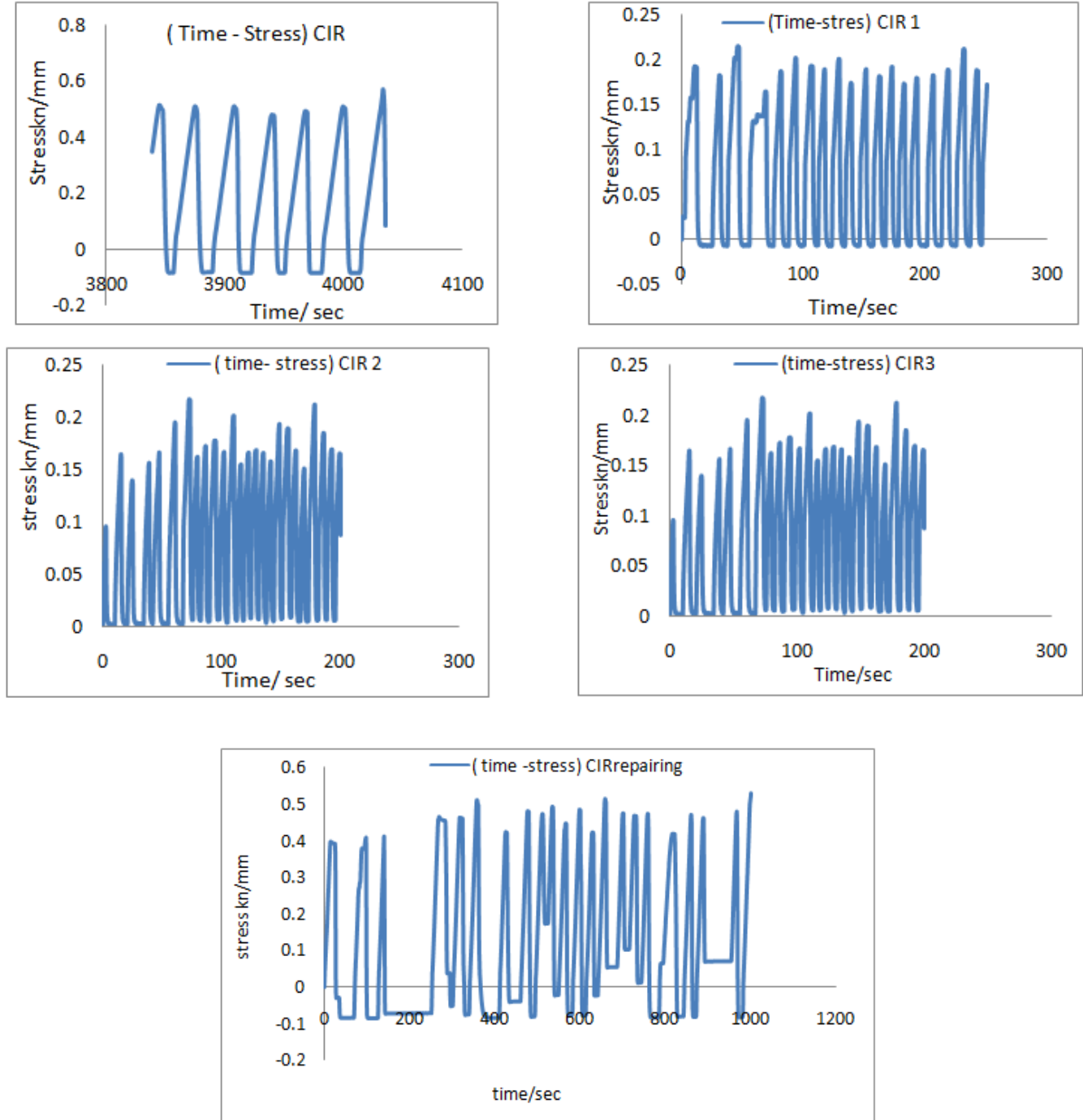

Shape8. The time- stresses Comparison of the behavior for the beams in the fatigue case.

\section{CONCLUSIONS}

Based on the experimental investigations and on the predicted behavior of the fatigue crack growth in steel beams reinforced

1- The fatigue crack growth of damaged steel beams can be effectively reduced by using CFRP reinforcement.

2- The fatigue behavior is significantly improved by increasing the strips layers reinforcement in the web, than the tension flange layers only by $1.2 \%$.

3- The crack growth rate is large at the beginning of the tests resulting in faster fatigue crack propagation.

4- The fatigue crack growth is very sensitive to the tensile force in the CFRP strips. The use of three reinforcement layers increases the tensile force in the reinforcement, resulting in a substantial increment of the fatigue life.

5- Reinforcement de-bonding plays an important role in the efficacy of the repair and it lessens the fatigue life.

6- The fatigue crack growth in cracked steel sections reinforced by using CFRP strips is a complex phenomenon governed by the adhesive behavior and by the interaction between the fatigue crack propagation in the steel section and the reinforcement de-bonding. This leads to a significant scatter of the fatigue crack growth curves in the experimental findings.

7- Static load tacked a smaller time to fail than fatigue loads about 10 times that was for the absorbing energy. 


\section{ACKNOWLEDGEMENTS}

The experimental tests were performed at the benha faculty of engineering Testing Laboratory of the Benha University. The financial support of it is gratefully acknowledged Thanks are also to Yousry B. I. Shaheen, Civil Department, Faculty of Engineering, Menoufia University, Egypt for his co'operating and helpful.

\section{REFERENCES}

[1] Kim YJ, Green MF, Fallis GJ. Repair of bridge girder damaged by impact loads with prestressed CFRP sheets. J. Bridge Eng ASCE 2008;13(1):15-23.

[2] Kim YJ, Yoon DK. Identifying critical sources of bridge deterioration in cold regions through the constructed bridges in North Dakota. J Bridge Eng ASCE2010;15(5):542-52.

[3] Harries KA. Structural testing of prestressed concrete girders from the Lake View Drive Bridge. J Bridge Eng ASCE 2009;14(1):78-92.

[4] Yail J. Kim, Kent A. HarriesFatigue behavior of damaged steel beams repaired with CFRP stripsEngineering Structures 33 (2011) 1491-1502.

[5] American Society of Civil Engineers (ASCE). Report card for America'sInfrastructure. Reston (VA, USA): American Society of Civil Engineers; 2005.

[6] Nozaka K, Shield CK, Hajjar JF. Effective bond length of carbon-fiber-reinforced polymer strips bonded to fatigued steel bridge I-girders. J Bridge Eng ASCE2005;10(1):195-205.

[7] O’Neill A, Harries KA, Minnaugh P. Fatigue behavior of adhesive systems used for externally-bonded FRP applications. In: Proc. 3rd int'l conf. durability \&field applications of FRP for const. Quebec City (QC, Canada); 2007.

[8] Jones S, Civjan S. Application of fiber reinforced polymer overlays to extendsteel fatigue life. J Compos Constr 2003:331-8.

[9] Tavakkolizadeh M, Saadatmanesh H. Fatigue strength of steel girdersstrengthened with carbon fiber reinforced polymer patch. J Struct Eng2003;129:186-96.

[10] Botong Zheng, Mina Dawood. Fatigue crack growth analysis of steel elements reinforced with shapememory alloy (SMA)/fiber reinforced polymer (FRP) composite patches. Composite Structures 164 (2017) 158-169.

[11] E. Ghafoori, M. Motavalli, Analytical calculation of stress intensity factor of cracked steel I-beams with experimental analysis and 3D digital image correlation measurements, Eng Fract Mech, 78 (2011), 3226-3242.

[12] X.L. Zhao, FRP strengthening of metallic structures subject to fatigue loading, in: Proceedings of Seventh National Conference on FRP in Construction, Hangzhou, China, October 2011, pp. 15-16.

[13] Pierluigi Colombi, Giulia Fava Fatigue crack growth in steel beams strengthened by CFRP strips, Theoretical and Applied Fracture Mechanics 85 (2016) 173-182.

Dr. Hala M. R. Abusafa. "TheExperimental investigation of the damaged B.F.I. Beamrepaired by CFRP under the Static and fatigue loads." International Journal of Engineering Research and Applications (IJERA) 7.7 (2017): 30-43. 